\title{
Fragmentation in small-scale confined blasting
}

Daniel Johansson*

Division of Mining and Geotechnical Engineering,

Luleå University of Technology,

SE 97187 Luleå, Sweden

Fax: + 46 (920) 491336

E-mail: Daniel.Johansson@1tu.se

${ }^{*}$ Corresponding author

\section{Finn Ouchterlony}

Swebrec, Swedish Blasting Research Centre,

Luleå University of Technology, Sweden

E-mail: Finn.Ouchterlony@ltu.se

\begin{abstract}
Design of sub-level blasting rounds and optimisation has become more important now when the sizes of the blasting rings get larger. Sufficient fragmentation is one of the key factors, and in confined blasting as in sub-level caving, this influences the mobilisation of the blasted ring. Model scale tests have been made to understand the mechanisms of rock breakage and therefore fragmentation under relatively confined conditions. By using the acoustic impedance between the blasted material and the confining debris, a relationship for fragmentation has been found depending on material, specific charge (powder factor) and physical properties of the debris. The results can be comparable with confined blasting in large scale.
\end{abstract}

Keywords: confined blasting; fragmentation; sub-level caving; granular material; debris.

Reference to this paper should be made as follows: Johansson, D. and Ouchterlony, F. (2011) 'Fragmentation in small-scale confined blasting', Int. J. Mining and Mineral Engineering, Vol. 3, No. 1, pp.72-94.

Biographical notes: Daniel Johansson holds a Master's Degree in Civil Engineering and a Licentiate Degree in Rock Mechanics and Rock Engineering from Luleå University of Technology (LTU). His mining experiences are in cut and fill mining operations and sub-level caving mining. He is currently a doctoral student at LTU under Professor Finn Ouchterlony. His research concerns blasting under confined conditions with respect to compaction and fragmentation, shock wave interactions and blast modelling.

Finn Ouchterlony was LKAB Professor in Detonics and Rock Blasting at the division of Geotechnology of the Department of Civil and Environmental Engineering at LTU. He was also a research manager of the Swedish Blasting Research Centre at LTU when this work was carried out. He received his $\mathrm{PhD}$ in Fracture Mechanics from the Royal Institute of Technology (KTH) in 1978. $\mathrm{He}$ is presently Guest Professor at the Montanuniversität Leoben in Austria. $\mathrm{He}$ has authored many papers in international journals as well as presented papers at international conferences. $\mathrm{He}$ is a member of the international 
organising committee of Fragblast conferences and of the editorial boards of the journals International Journal of Rock Mechanics and Mining Sciences and Rock Mechanics and Rock Engineering.

\section{Introduction}

In a mass mining method such as sub-level caving (Figure 1), the mining operation involves confined blasting conditions, i.e., the ore to be blasted is restrained by the caving material (debris) in the hanging wall (Figure 1). This is influencing the free swell as in open pit operations. Full-scale investigations have been done by others (Power, 2004a-b; Gustafsson, 1998), but they showed different views and models on how this interface is influencing the caving of the ore. The specific charge (Am. English powder factor) in the SLC-blast ring of LKAB (Figure 2) can vary from $0.3 \mathrm{~kg} / \mathrm{m}^{3}$ to $2.8 \mathrm{~kg} / \mathrm{m}^{3}$ (Selldén, 2001) with a burden of $3 \mathrm{~m}$.

Figure 1 Sub-level caving method

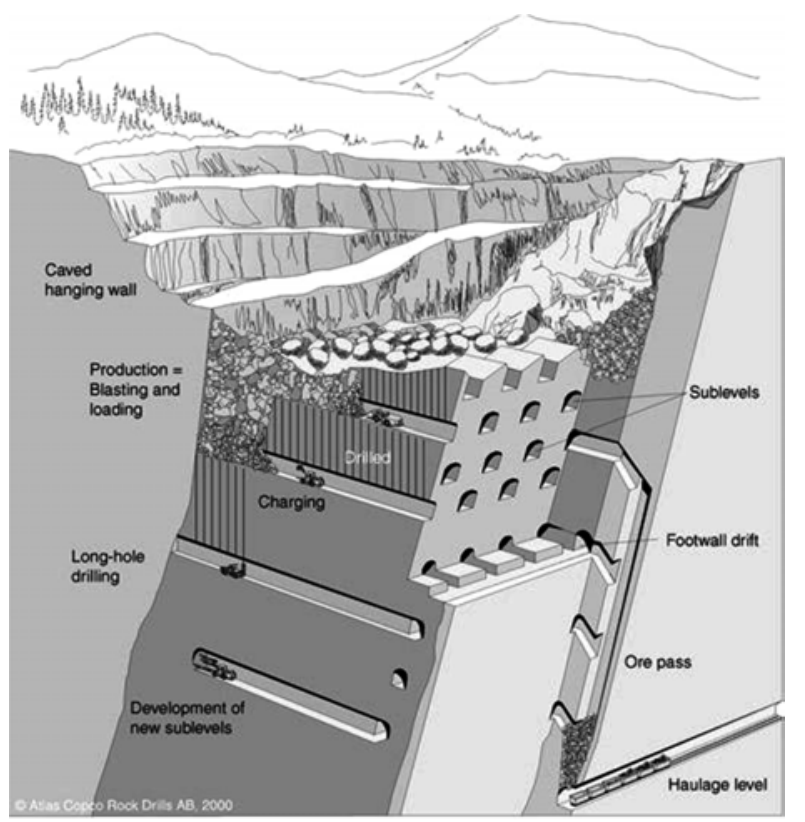

Source: Atlas Copco (2004)

Caved material from the hanging wall acts as a wave trap in front of the SLC-ring and will influence the mobilisation of the blasted ring in the SLC-operation (Cullum, 1974). There are two major factors that will influence the blasted ore's capability to flow when the loading starts; fragmentation and swell. Full-scale investigations of these are nearly impossible to do, since the mining method itself prohibits detailed analysis of the fragmentation along the fan. Sieving of parts of a blasted ring has been made before (Maripuu, 1968; Power, 2004a, 2004b; Wimmer et al., 2008), but without analysis of the effect confining material and of specific charge. 
Therefore, the properties of the caved debris from the hanging-wall have never been investigated and determined. This is important, since the caving process is influenced by the stiffness and the cohesion of the waste rock, which is dependent in some way on the compaction that the blast ring contributes to.

Figure 2 Example of a fan hole drilling round or blast ring in sub-level caving

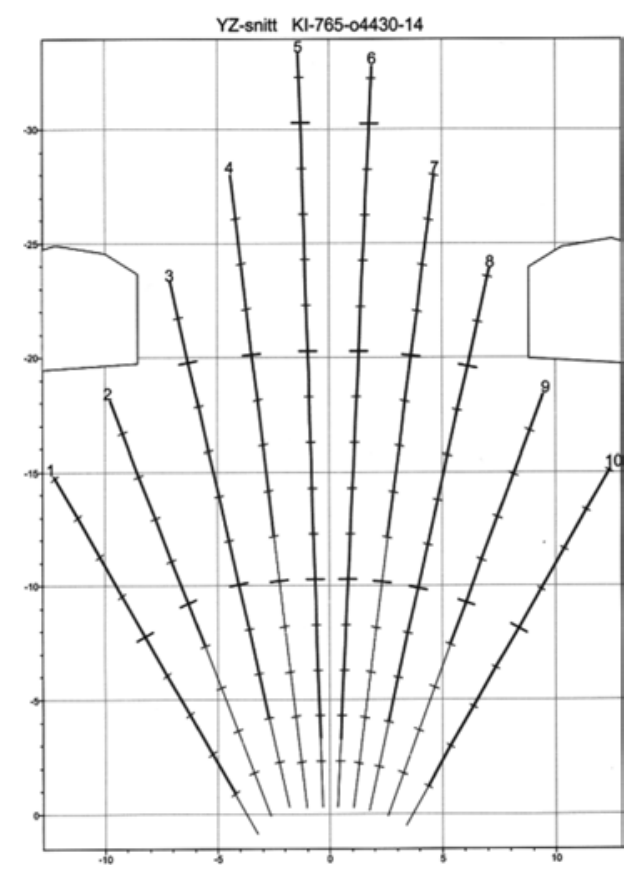

Model-scale tests have been made to understand the mechanisms of rock breakage and therefore fragmentation under relatively confined conditions. Earlier findings for free face conditions have shown that small-scale tests in many ways are comparable with large-scale tests (Ouchterlony and Moser, 2006). The demands on the set-up used here were that it had to give repeatable results and have small boundary effects. The tests involved two input materials; a model material and a confining material and it was important to separate them post-blast. One alternative used in earlier research was magnetic model material, which could be separated by magnetic methods (Miklautsch, 2002) and another alternative is to use pigments to visually separate the two materials (Svahn, 2003).

\section{Methodology}

It was decided to investigate blasting under confined environment (debris) in model scale. Either specimen fragmentation or compaction of debris was measured. The geometry chosen was cylinders of magnetic material with an axial charge of PETN cord, the model surrounded either by air (Figure 3) or by a layer of crushed rock (caving material or debris, confined specimen - Figure 4). The cylinders were of size $\varnothing 140 \times 280$ $\mathrm{mm}$ with a centred hole for the explosive. To simulate the confined environment, the 
cylinders were surrounded by a steel cylinder with an inner diameter of $309 \mathrm{~mm}$ for the fragmentation shots and for the compaction shots the steel cylinder was replaced with a plastic tube of similar size (Johansson, 2010). Debris with different properties was packed in the annulus between the two cylinders. By using cylindrical specimens for the tests, the geometry as an influencing factor could be minimised. Free face shots were used as a base line for quantifying the effect of the confinement on the fragmentation. To create a robust set-up with reliable material properties, the model material and the confining debris properties had to be as repeatable as possible.

Figure 3 Set-up for free face tests

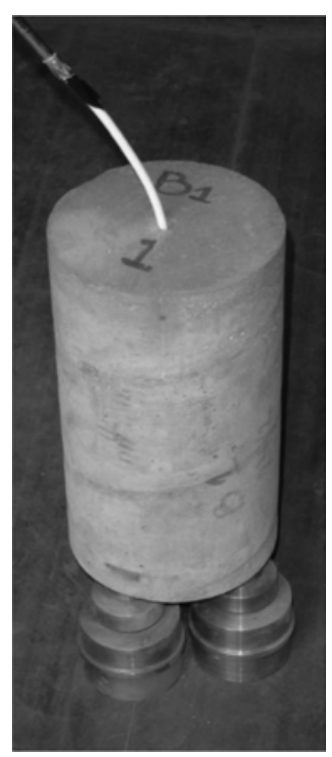

Figure 4 Test set-up for confined shots

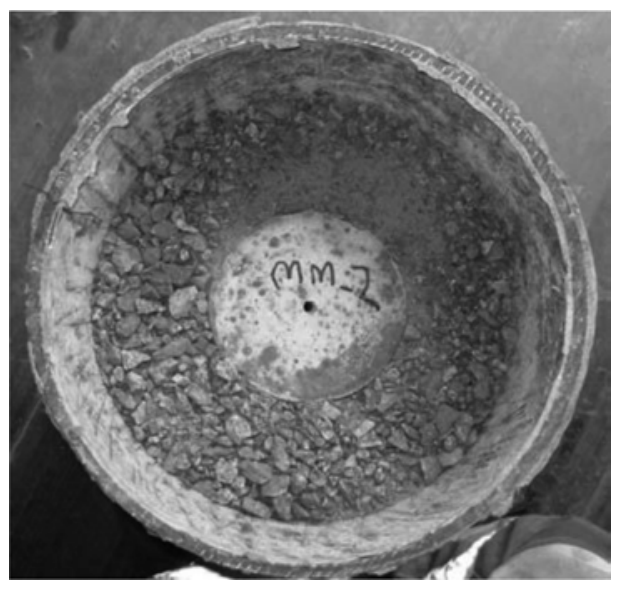

Magnetite as a testing material is not really suitable for small-scale testing in a confined environment, owing to its variable properties (Johansson, 2008). Trials were, however, made on $\varnothing 190 \mathrm{~mm}$ magnetite cores $\left(\mathrm{Mg}_{1}\right)$, taken out of boulders in the mine for 
establishing the fragmentation similarities between ore and model material. Thereafter, a complete test series on $\varnothing 140 \mathrm{~mm}$ cores $\left(\mathrm{Mg}_{2}-\mathrm{Mg}_{5}\right)$ was made. The selection of ore types was made on the basis of their variable blasting properties as judged by the mine staff. The physical properties of these magnetite qualities are shown in Table 1. The rock mechanical and geological properties of the four magnetite qualities were supplied by LKAB. Data from the exact specimen position was not always available, and in those cases, data were taken from nearby drifts instead.

Table 1 Physical properties of the tested magnetite ore types

\begin{tabular}{lcccc}
\hline Spec name/Drift no. & $\mathrm{Mg}_{2} / 101$ & $\mathrm{Mg}_{3} / 148$ & $\mathrm{Mg}_{4} / 201$ & $\mathrm{Mg}_{5} / 401$ \\
\hline E-modulus $(\mathrm{GPa})$ & 84 & 78 & 84 & 83 \\
Poisson's ratio $v$ & 0.29 & 0.37 & 0.35 & 0.32 \\
Brazilian tensile strength $\sigma_{B T}(\mathrm{MPa})$ & 7.7 & 13.6 & 8.9 & 9.2 \\
UCS $(\mathrm{MPa})$ & 141 & 174 & 143 & 176 \\
Average density $\rho\left(\mathrm{kg} / \mathrm{m}^{3}\right)$ & 4938 & 4972 & 5030 & 4913 \\
P-wave speed c $p(\mathrm{~m} / \mathrm{s})^{1}$ & & & & \\
- Along the ore & 6270 & 6270 & 6270 & 6270 \\
- Across the ore & 4881 & 4881 & 4881 & 4881 \\
\hline
\end{tabular}

${ }^{1}$ Measured in-situ at one location in the mine.

Source: Liu et al. (2005)

The magnetite cylinders had $\varnothing 8 \mathrm{~mm}$ holes drilled out in the magnetite cylinders and the samples were charged with $20 \mathrm{~g} / \mathrm{m}$ cord, which gives a specific charge of $1.31 \mathrm{~kg} / \mathrm{m}^{3}$ or $0.26 \mathrm{~kg} /$ ton based on an approximate magnetite density of $5000 \mathrm{~kg} / \mathrm{m}^{3}$.

A model material made of mortar (Table 2) mixed with magnetite fines showed a good repeatability between different batches, as the standard deviation of $x_{50}$ for the free face shots with $20 \mathrm{~g} / \mathrm{m}$ cord was less than $1 \mathrm{~mm}, x_{50}=15.2 \pm 1.0 \mathrm{~mm}$ over 19 shots (Johansson, 2008). The trials indicated a similar fragmentation as magnetite, when the specific charge $(q)$ was the same in $\mathrm{kg} / \mathrm{m}^{3}$.

Table 2 Magnetic mortar recipe. Mortar properties given in Table 4

\begin{tabular}{lc}
\hline Ingredient & $\%$ \\
\hline Portland cement (Cementa) & 25.6 \\
Water & 12.6 \\
Glenium 51 (plasticiser) & 0.3 \\
Magnetite powder (Minelco KPC) & 29.7 \\
Quartz sand (SIKA) & 31.1 \\
Tributylphosphate (defoamer) & 0.1 \\
\hline
\end{tabular}

One or two reference shots were always used to compare different mortar batches and campaigns. Since already very small deviations in a small scale can affect the interpreted result in large scale, it was of importance that the not tested parameters (VOD, density, 
size distributions of the debris, etc.) were held as constant as possible. The geometrical similarity is as seen not the same as in full-scale conditions, but this does not interfere that much with studies of the phenomenon of confined blasting. The specific charge was varied by using PETN cord with strengths varying from $40 \mathrm{~g} / \mathrm{m}$ to $1.5 \mathrm{~g} / \mathrm{m}$ (Table 3 ). In total, six different specific charges have been used and the coupling ratio, i.e., the charge diameter to hole diameter ratio, was held relatively constant by casting holes of different diameters in the specimens. The reference value of the standard SLC-operation at LKAB amounts to $1.3 \mathrm{~kg} / \mathrm{m}^{3}$ (Selldén, 2001). In the tests with PETN, the strength of $20 \mathrm{~g} / \mathrm{m}$ in a $\varnothing 140 \mathrm{~mm}$ cylinder results in the same specific charge.

Table 3 PETN-cord properties

\begin{tabular}{lcccccc}
\hline PETN cord strength $(\mathrm{g} / \mathrm{m})$ & 40 & 20 & 10 & 5 & 3 & Mean \pm std. dev. \\
\hline VOD $(\mathrm{m} / \mathrm{s})$ & 7390 & 7683 & 7243 & 7113 & 7201 & $7309 \pm 207$ \\
Specific charge $q\left(\mathrm{~kg} / \mathrm{m}^{3}\right)$ & 2.6 & 1.3 & 0.65 & 0.33 & 0.2 & \\
Coupling ratio & 2 & 2.3 & 2.7 & 2.8 & 3 & \\
\hline
\end{tabular}

Every sample was measured and weighed. The P-wave measurements were made on $\varnothing 42 \mathrm{~mm}$ cores by a wave trigger from CNS instruments in combination with a LeCroy 9424, $350 \mathrm{MHz}$ oscilloscope.

Four kinds of granular material were tested for their effects on the compaction. They are described in Table 5. The $x_{50}=8 \mathrm{~mm}$ of material \#1 was chosen to be about in the same proportion to burden $R=70 \mathrm{~mm}$ as the commonly used estimate that $x_{50} \approx 250 \mathrm{~mm}$ in an SLC-ring with $3 \mathrm{~m}$ burden. Proper fractions to make up a Swebrec distribution (Ouchterlony, 2005) were used (Table 5).

Material \#1 was also tested with the Proctor compaction method (Johansson, 2008), to determine the maximum practical density. It was not possible to make such tests on all materials owing to heavy crushing of the low strength and multi-phase materials.

Using the Swebrec-function (Ouchterlony, 2005, 2009a) as an evaluation tool of the sieving curves, estimating average particle size $\left(x_{50}\right)$ and fragmentation behaviour will ensure that the fragmentation behaviour is reasonable and representative of other blasting methods.

It has been shown that this function can describe the sieved data with a coefficient of determination $R^{2}$ better than 0.995 in $95 \%$ of the hundreds of cases encountered from bench blasts in quarries, reef blasting, small-scale blasting and crushing. It contains three parameters, $x_{50}, x_{\max }$ and an undulation parameter $b$ and can be seen in equation (1).

$$
\left.\mathrm{P}(\mathrm{x})=1 /\left\{1+\left[\ln \left(\mathrm{x}_{\max } / \mathrm{x}\right) / \ln \mathrm{x}_{\max } / \mathrm{x}_{50}\right)\right]^{\mathrm{b}}\right\} .
$$

A suitable approach when working in model-scale is to derive a proper scale for the input parameters (Taylor, 1974). These can be divided in three sub-groups in terms of properties: Blasting material, Explosive and Confining material (Figure 5). The physics in confined blasting is mainly cracking of the model material and crushing of the confining aggregate. Therefore, suitable strength parameters ought to be tensile strength $\left(\sigma_{B T}\right)$ or fracture toughness for the model material and compressive strength for the confining material (UCS). 
Table 4 Physical properties of the magnetic mortar

\begin{tabular}{lcccc}
\hline $\begin{array}{l}P \text {-wave velocity } c_{p} \\
{[\mathrm{~m} / \mathrm{s}]}\end{array}$ & $\begin{array}{c}\text { Uniaxial compressive } \\
\text { strength UCS } \\
{[\mathrm{MPa}]}\end{array}$ & $\begin{array}{c}\text { Brazilian tensile } \\
\text { strength } \sigma_{B t} \\
{[\mathrm{MPa}]}\end{array}$ & $\begin{array}{c}\text { Poisson's } \\
\text { ratio } v \\
{[-]}\end{array}$ & $\begin{array}{c}\text { Density } \rho \\
{\left[\mathrm{kg} / \mathrm{m}^{3}\right]}\end{array}$ \\
\hline $3808 \pm 73$ & $50.7 \pm 4.8$ & $5.23 \pm 0.34$ & 0.22 & $2511 \pm 25$ \\
\hline \multicolumn{2}{c}{ Source: } & Johansson $(2008)$
\end{tabular}

Table 5 Tested granular materials

\begin{tabular}{|c|c|c|c|c|c|}
\hline $\begin{array}{l}\text { Debris } \\
\text { material no. }\end{array}$ & Description & $\begin{array}{c}\text { Porosity } \\
p_{a}[\%]\end{array}$ & $\begin{array}{c}c_{p a} \\
{[\mathrm{~m} / \mathrm{s}]}\end{array}$ & $\begin{array}{c}\text { Average } \\
{[\mathrm{kg} / \mathrm{m}]}\end{array}$ & $\begin{array}{l}\text { Swebrec distribution } \\
\text { parameters }\end{array}$ \\
\hline$\# 1$ & $\begin{array}{l}\text { Crushed granite } \\
\mathrm{UCS}=240 \mathrm{MPa}\end{array}$ & 36 & 1168 & $1696^{1}$ & $\begin{array}{l}x_{50}=8 \mathrm{~mm}, \\
x_{\max }=16 \mathrm{~mm} \text { and } \\
b=2.2\end{array}$ \\
\hline$\# 2$ & $\begin{array}{l}\text { Crushed granite, } \\
0-16 \mathrm{~mm} \text {, with Plaster } \\
\text { of Paris }\end{array}$ & 30 & $900^{2}$ & 1868 & - \\
\hline \#3 & Crushed granite, $0-16 \mathrm{~mm}$ & 20 & 1047 & 2050 & $\begin{array}{l}x_{50}=4 \mathrm{~mm}, \\
x_{\max }=16 \mathrm{~mm} \text { and } \\
b=1.3\end{array}$ \\
\hline$\# 4$ & $\begin{array}{l}\text { Crushed non-magnetic } \\
\text { mortar, } 0-16 \mathrm{~mm} \\
\mathrm{UCS}=50 \mathrm{MPa}\end{array}$ & 32 & 596 & 1428 & $\begin{array}{l}x_{50}=8 \mathrm{~mm} . \\
x_{\max }=19 \mathrm{~mm} \text { and } \\
b=2.6\end{array}$ \\
\hline
\end{tabular}

${ }^{1}$ Max density as measured by the Proctor method was $1980 \mathrm{~kg} / \mathrm{m}^{3}$ for debris $\# 1$.

${ }^{2}$ For debris \#2, $c_{\mathrm{pa}}$ was measured using an emulsion explosive.

Figure 5 Input parameters for dimensional analysis

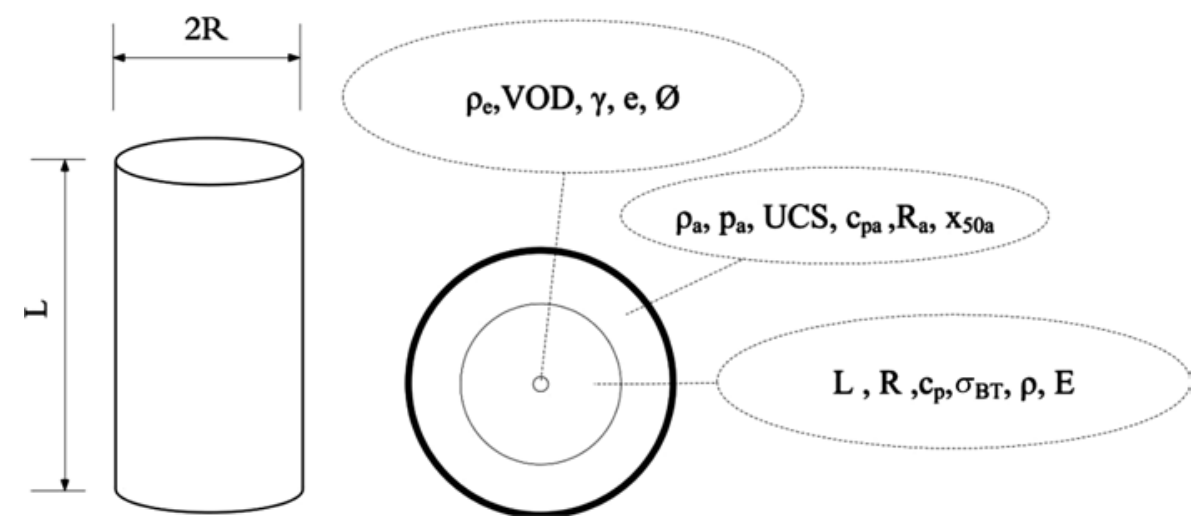

These groups involve 17 different parameters that describe the conditions:

- $\quad$ Blasting material: Specimen height $L(\mathrm{~m})$, radius $R(\mathrm{~m})$, density $\rho\left(\mathrm{kg} / \mathrm{m}^{3}\right)$, modulus of elasticity $E\left(\mathrm{~N} / \mathrm{m}^{2}\right)$, wave speed $c_{p}(\mathrm{~m} / \mathrm{s})$ and strength parameter $\sigma_{B T}\left(\mathrm{~N} / \mathrm{m}^{2}\right)$

- Explosive: Density of the explosive $\rho_{e}\left(\mathrm{~kg} / \mathrm{m}^{3}\right)$, velocity of detonation VOD $(\mathrm{m} / \mathrm{s})$, explosive energy $e(\mathrm{MJ} / \mathrm{kg}), \gamma$ (adiabatic constant) and charge diameter $\varnothing(\mathrm{m})$ 
- Aggregate: Degree of packing $\rho_{a}\left(\mathrm{~kg} / \mathrm{m}^{3}\right)$, porosity $p_{a}(\%)$, strength parameter UCS $\left(\mathrm{N} / \mathrm{m}^{2}\right), R_{a}$ (layer thickness in $\left.\mathrm{m}\right), x_{50 \mathrm{a}}$ (average size in $\mathrm{m}$ ) and wave speed $c_{p a}(\mathrm{~m} / \mathrm{s})$.

To reduce the number of variables in the process, it is assumed to be a $2 \mathrm{D}$ situation ( $\mathrm{L}$ vanishes) so that the detonation details are irrelevant. The latter phenomenon is not investigated (VOD and $\gamma$ vanish). The remaining parameters in the sub-group, $\varnothing$ and $\rho_{\mathrm{e}}$, could be replaced with the term specific charge $q\left(\mathrm{~kg} / \mathrm{m}^{3}\right)$, since this is a better description of the explosive effect. The number of parameters $(\mathrm{m})$ is 13 by this rearrangement.

Let the average fragmentation of the blasted material $x_{50}$ be in focus and the normalisation dimensions are $R, \rho$ and $c_{p}(n=3)$. Then

$$
x_{50} / R=F\left(\Pi_{1}, \Pi_{2}, \Pi_{3}, \Pi_{4}, \cdots \Pi_{\mathrm{m}-\mathrm{n}}\right),
$$

where $\Pi_{\mathrm{i}}$ is a dimensionless number.

According to Buckingham's theorem, the number of discrete and independent products that can be formed is equal to the difference between the number of parameters and dimensions, i.e., $\mathrm{m}-\mathrm{n}=10$. In this case, this will be as follows:

$$
x_{50} / R=F\left(q / \rho, \rho_{a} / \rho, p_{\mathrm{a}}, E / \rho c_{p}{ }^{2}, R_{\mathrm{a}} / R, x_{50 \mathrm{a}} / R, \mathrm{UCS} / \rho c_{p}{ }^{2}, \sigma_{B T} / \rho c_{p}{ }^{2}, e / c_{p}{ }^{2}, c_{p a} / c_{p}\right) .
$$

From this, the $\Pi$-groups should be set and analysed in relationship with full-scale conditions (Table 6). If there exists good agreement between small-scale and full-scale $\Pi: s$, the model's results should be scalable.

Table 6 Estimated relationship between full-scale and small-scale conditions (magnetic mortar) after dimensional analysis

\begin{tabular}{llc}
\hline$\Pi$ & Small-scale & Full-scale \\
\hline$\Pi_{1}=q / \rho$ & $0.00004-0.00104$ & 0.00026 \\
$\Pi_{2}=\rho_{\mathrm{a}} / \rho$ & For debris $1=0.66$ & 0.4 \\
& For debris $2=0.72$ & \\
& For debris $3=0.83$ & \\
& For debris $4=0.55$ & \\
& $20-36 \%$ & $25-35 \%$ \\
$\Pi_{3}=p_{a}$ & 0.6 & $0.4-0.65$ \\
$\Pi_{4}=E / \rho c_{p}^{2}$ & 1.21 & - \\
$\Pi_{5}=R_{a} / R$ & 0.11 & 0.083 \\
$\Pi_{6}=x_{50 \mathrm{a}} / R$ & For debris $1=5.5$ & 1.3 \\
$\Pi_{7}=\mathrm{UCS} / \rho c_{p}^{2}$ & For debris $4=1.4$ & \\
$\Pi_{8}=\sigma_{\mathrm{BT}} / \rho c_{p}^{2}$ & 0.144 & 0.080 \\
$\Pi_{9}=e / c_{p}^{2}$ & 0.41 & 0.13 \\
$\Pi_{10}=c_{p a} / c_{p}$ & For debris $1=0.31$ & - \\
& For debris $2=0.24$ & \\
& For debris $3=0.28$ & \\
& For debris $4=0.16$ &
\end{tabular}


Some of these results are not measurable in full-scale conditions, so some parameters are estimated and others have to be neglected. This can be seen in $\Pi_{5}$ and $\Pi_{10}$ where the model does not have a corresponding value in full scale.

The case for $\Pi_{5}\left(=R_{\mathrm{a}} / R\right)$ the full-scale behaviour is very difficult to determine, so a detailed comparison is not possible. The trials indicated similar fragmentation between the model material and some of the magnetite samples, therefore, $\Pi_{5}$ may be neglected in this comparison.

In full scale, the used explosive is an emulsion and it is impossible to use in small-scale conditions owing to its large critical diameter (Johansson, 2008). PETN has ideal detonation properties, more or less independent of diameter, which indicates that it is a suitable explosive source in small scale. As seen in Table $6, \Pi_{9}$ is higher in small scale than in full-scale conditions. To compensate for the lower energy content and blast hole pressure of the emulsion explosive, the PETN-cords were decoupled, which may then simulate the full-scale conditions better.

Combining $\Pi_{2}$ and $\Pi_{10}$, gives an impedance ratio $Z_{a} / Z$, which is more relevant and understandable for these conditions.

The specimens were blasted inside a closed, rubber clad container. The initiation was made by a Nonel Unidet blasting cap taped end on to the cord. The free fragmentation specimens stood on three aluminium supports (Figure 3), the confined ones on fibreboard to prevent the debris from flowing out. The container was carefully swept out after each shot. The fragments were put in a smaller, sealed container and then screened at an accredited road laboratory. The confined shots did also undergo magnet separation, to receive two separate sieving curves of the blasted material and of the confining material.

\section{Results}

More than 80 blast tests have been made with this set-up, either under free face or confined conditions both for magnetite and for magnetic mortar (Figure 6). Test series investigating explosive source, coupling and direction of initiation have also been made and their effects were found to be marginal except for the explosive source. When the PETN-cord was replaced with an emulsion however, the detonation properties varied too much under the small diameter conditions. It was clear that the critical diameter was close for that specific emulsion.

Figure 6 To the left: example of free face shots after blast. To the right: example of confined shots after blast

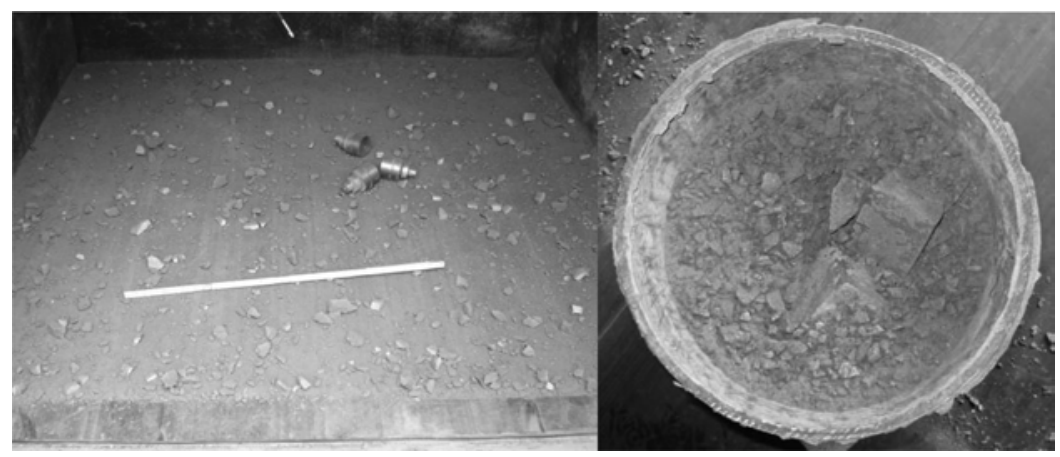




\section{$3.1 x_{50}$ vs. model material}

The magnetite was evaluated and compared with magnetic mortar during two test series. For 4 types of magnetite $\left(\mathrm{Mg}_{2}-\mathrm{Mg}_{5}\right)$, 4 shots each were made: 2 free and 2 confined. A trial campaign with a magnetite boulder material $\left(\mathrm{Mg}_{1}\right)$ was also made. PETN with the strength of $20 \mathrm{~g} / \mathrm{m}$ was selected, which gave a specific charge of $1.31 \mathrm{~kg} / \mathrm{m}^{3}$ or $0.27 \mathrm{~kg} /$ ton. The surrounding debris was debris \#1 (aggregate $0-16 \mathrm{~mm}$ ).

The fragmentation had considerable variation (Figure 7), the $\mathrm{Mg}_{4}$ quality was hardest to blast and the $\mathrm{Mg}_{3}$ quality the easiest. For the free specimens, $\mathrm{x}_{50}$ lies in the range $13.3-28.3 \mathrm{~mm}$ and for the confined specimens the range was $21.9-34.6 \mathrm{~mm}$. The confined magnetite specimens had always coarser fragmentation than the free specimens for all four qualities. The difference was on average $37 \%$ and there were no overlaps within each quality.

The fragmentation curves show parallel shifts depending on magnetite type with one exception $\left(\mathrm{Mg} 33_{3}\right.$ 05). The slopes at $x_{50}\left(\mathrm{~s}_{50}\right)$ are roughly the same for all magnetite specimens varying from 0.0175 to 0.0387 depending on confinement and ore type (Table 7).

Table 7 Swebrec function parameters for magnetite specimens from curve fitting

\begin{tabular}{lcccccl}
\hline Magnetite & $x_{50}$ & $x_{\max }$ & $b$ & $s_{50}$ & $R^{2}$ & Confinement \\
\hline Mg_2_1_05 & 20.5 & 61.2 & 2.361 & 0.0263 & $>0.999$ & Free \\
Mg_2_2_05 & 20.4 & 66.5 & 2.495 & 0.0259 & $>0.999$ & Free \\
Mg_2_3_05 & 26.0 & 94.6 & 3.115 & 0.0232 & $>0.999$ & Debris \#1 \\
Mg_2_4_05 & 26.6 & 65.3 & 2.376 & 0.0249 & $>0.999$ & Debris \#1 \\
Mg_3_1_05 & 13.7 & 51.3 & 2.191 & 0.0303 & $>0.998$ & Free \\
Mg_3_2_05 & 13.3 & 46.7 & 2.589 & 0.0387 & $>0.999$ & Free \\
Mg_3_3_05 & 21.9 & 79.1 & 2.737 & 0.0243 & $>0.999$ & Debris \#1 \\
Mg_3_4_05 & 22.6 & 59.4 & 2.112 & 0.0242 & $>0.999$ & Debris \#1 \\
Mg_4_1_05 & 28.3 & 123.0 & 2.907 & 0.0200 & $>0.998$ & Free \\
Mg_4_2_05 & 22.6 & 90.1 & 2.980 & 0.0200 & $>0.999$ & Free \\
Mg_4_3_05 & 34.1 & 71.9 & 2.034 & 0.0175 & $>0.999$ & Debris \#1 \\
Mg_4_4_05 & 32.9 & 78.0 & 2.273 & 0.0238 & $>0.999$ & Debris \#1 \\
Mg_5_1_05 & 22.2 & 52.7 & 2.003 & 0.0261 & $>0.999$ & Free \\
Mg_5_2_05 & 16.0 & 60.8 & 2.995 & 0.0230 & $>0.999$ & Free \\
Mg_5_3_05 & 24.7 & 72.1 & 2.431 & 0.0276 & $>0.998$ & Debris \#1 \\
Mg_5_4_05 & 26.0 & 94.6 & 3.115 & 0.0351 & $>0.999$ & Debris \#1 \\
\hline
\end{tabular}

\section{$3.2 x_{50}$ vs. $\Pi_{1}$}

Proceeding with the results from the dimensional analysis, the identified factor $\Pi_{1}$ has been further analysed vs. the fragmentation results for the magnetic mortar specimens, one example can be seen in Figure 8. A total number of 62 data points with magnetic mortar specimens were used in this analysis (Table 8). In Figure 9 the $x_{50}$ values have been plotted vs. $\Pi_{1}$ for all confining conditions. The effect of confinement is clearly seen, with individual trends for each confining state. 
Figure 7 Selected fragment size distributions for four different magnetite types and magnetic mortar under free face conditions. Specimen $\mathrm{Mg} \_2 \_1 \_05$ consists of quality $\mathrm{Mg}_{2}$, etc, MM1 of magnetic mortar

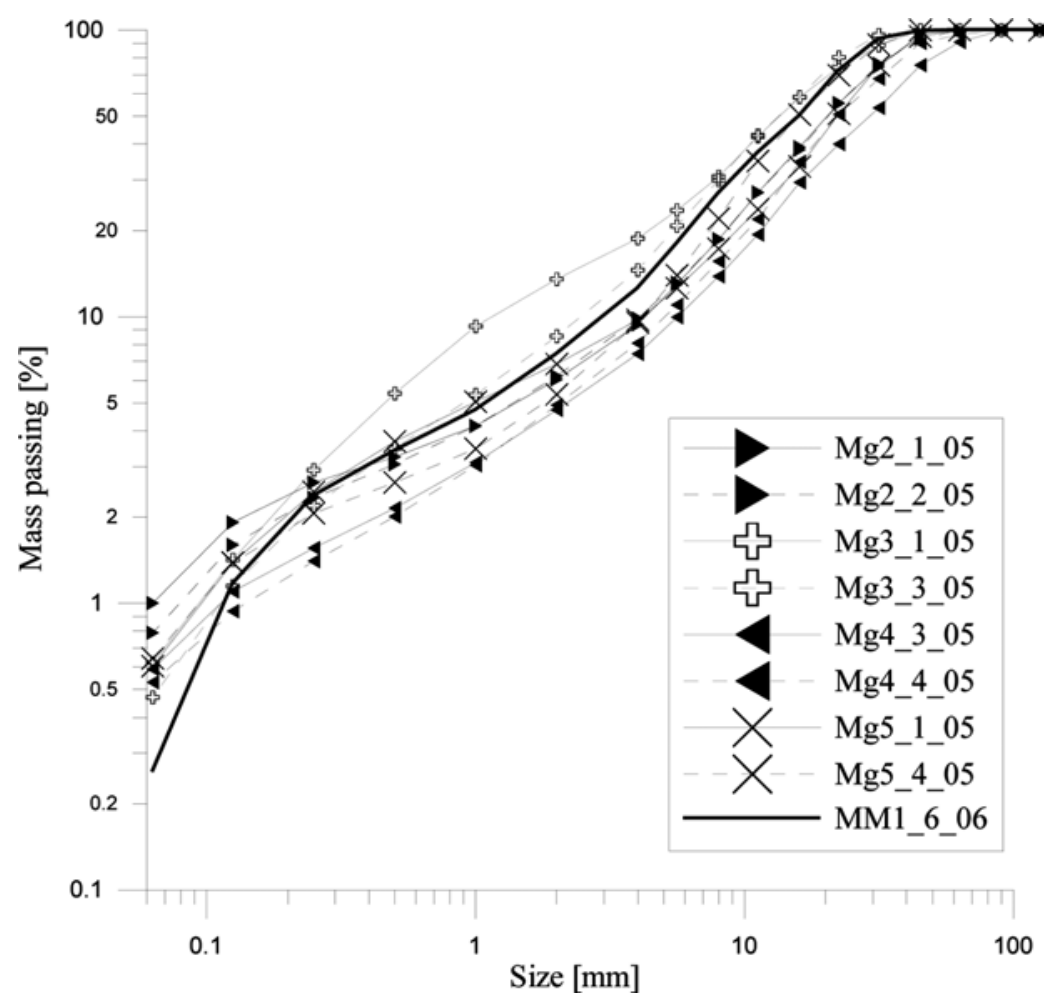

Figure 8 Swebrec function fit to data for specimen MM_5_1_05

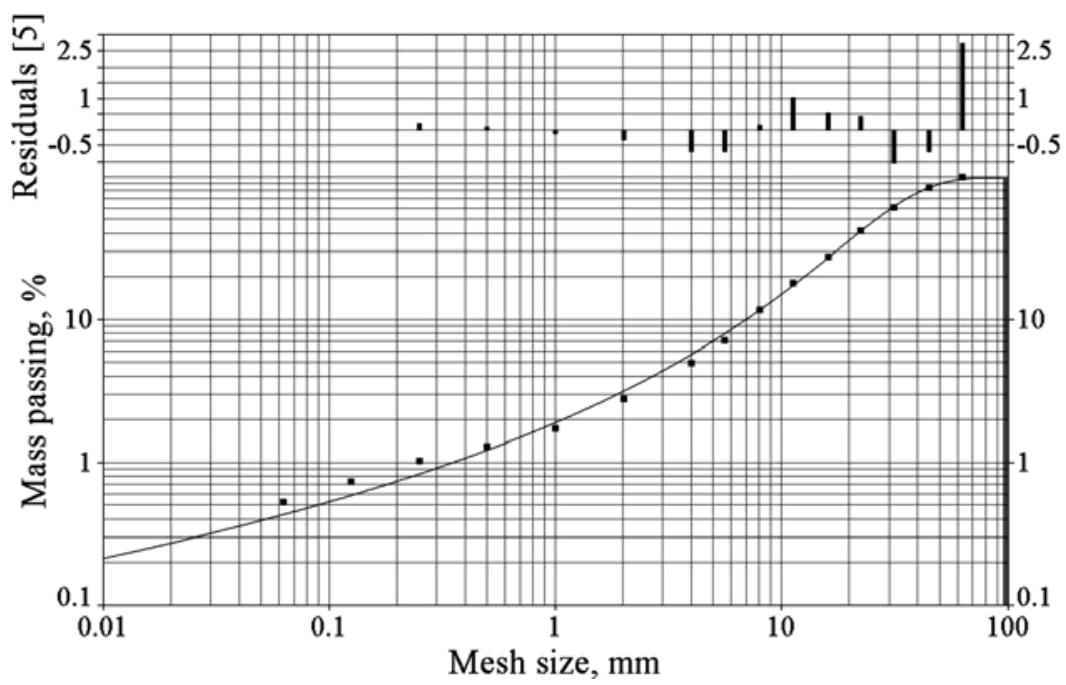


Table 8 Swebrec function parameters for magnetic mortar specimens from curve fitting

\begin{tabular}{|c|c|c|c|c|c|c|c|}
\hline Mortar & $\Pi_{1}$ & $x_{50}$ & $x_{\max }$ & $b$ & $s_{50}$ & $R^{2}$ & Confinement \\
\hline MM_0_2_04 & 0.00026 & 47.9 & 123.1 & 2.628 & 0.0145 & $>0.998$ & Debris \#1 \\
\hline MM_0_5_04 & 0.00026 & 48.8 & 108.2 & 2.358 & 0.0152 & $>0.998$ & Debris \#1 \\
\hline MM_1_7_05 & 0.00052 & 24.7 & 57.8 & 2.239 & 0.0267 & $>0.997$ & Debris \#1 \\
\hline MM_2_C_05 & 0.00052 & 30.5 & 89.0 & 2.500 & 0.0191 & $>0.997$ & Debris \#1 \\
\hline MM_2_D_05 & 0.00052 & 27.0 & 69.7 & 2.230 & 0.0218 & $>0.998$ & Debris \#1 \\
\hline MM_2_3_05 & 0.00052 & 26.8 & 77.8 & 2.638 & 0.0231 & $>0.997$ & Debris \#1 \\
\hline MM_2_11_05 & 0.00052 & 25.3 & 57.4 & 2.210 & 0.0267 & $>0.998$ & Debris \#1 \\
\hline MM_2_9_05 & 0.00052 & 24.3 & 55.4 & 2.117 & 0.0264 & $>0.998$ & Debris \#1 \\
\hline MM_3_6_05 & 0.00052 & 32.8 & 81.0 & 2.369 & 0.0200 & $>0.999$ & Debris \#1 \\
\hline MM_5_1_05 & 0.00104 & 25.9 & 96.2 & 3.157 & 0.0232 & $>0.999$ & Debris \#1 \\
\hline MM_5_8_05 & 0.00026 & 48.1 & 79.3 & 1.897 & 0.0197 & $>0.998$ & Debris \#1 \\
\hline MM_7_12_06 & 0.00052 & 30.8 & 67.0 & 2.184 & 0.0228 & $>0.998$ & Debris \#1 \\
\hline MM_12_6_07 & 0.00026 & 53.1 & 90.0 & 2.196 & 0.0196 & $>0.998$ & Debris \#1 \\
\hline MM_12_7_07 & 0.00026 & 55.9 & 98.8 & 2.367 & 0.0186 & $>0.998$ & Debris \#1 \\
\hline MM_12_8_07 & 0.00026 & 61.7 & 90.0 & 1.905 & 0.0204 & $>0.999$ & Debris \#1 \\
\hline MM_12_9_07 & 0.00026 & 59.2 & 90.0 & 2.445 & 0.0247 & $>0.999$ & Debris \#1 \\
\hline MM_12_10_07 & 0.00052 & 37.9 & 75.4 & 2.127 & 0.0204 & $>0.998$ & Debris \#1 \\
\hline MM_13_5_07 & 0.00052 & 39.0 & 100.0 & 2.513 & 0.0171 & $>0.999$ & Debris \#1 \\
\hline MM_13_6_07 & 0.00052 & 33.3 & 81.7 & 2.331 & 0.0195 & $>0.999$ & Debris \#1 \\
\hline MM_13_7_07 & 0.00052 & 38.0 & 114.6 & 2.814 & 0.0168 & $>0.998$ & Debris \#1 \\
\hline MM_13_8_07 & 0.00104 & 18.8 & 82.1 & 2.982 & 0.0269 & $>0.998$ & Debris \#1 \\
\hline MM_13_9_07 & 0.00104 & 17.9 & 51.8 & 2.390 & 0.0314 & $>0.999$ & Debris \#1 \\
\hline MM_13_10_07 & 0.00104 & 16.9 & 59.5 & 2.634 & 0.0309 & $>0.999$ & Debris \#1 \\
\hline MM_14_1_07 & 0.00104 & 17.7 & 63.0 & 2.474 & 0.0275 & $>0.999$ & Debris \#1 \\
\hline MM_15_10_07 & 0.00104 & 19.0 & 78.1 & 2.935 & 0.0300 & $>0.999$ & Debris \#1 \\
\hline MM_15_11_07 & 0.00104 & 19.1 & 57.2 & 2.516 & 0.0336 & $>0.999$ & Debris \#1 \\
\hline MM_15_12_07 & 0.00104 & 14.8 & 53.8 & 2.563 & 0.0336 & $>0.998$ & Debris \#1 \\
\hline MM_7_8_06 & 0.00026 & 72.3 & 125.0 & 2.987 & 0.0189 & $>0.997$ & Debris \#2 \\
\hline MM_7_13_06 & 0.00052 & 43.1 & 90.0 & 2.417 & 0.0190 & $>0.999$ & Debris \#2 \\
\hline MM_7_15_06 & 0.00104 & 25.0 & 113.8 & 3.455 & 0.0228 & $>0.998$ & Debris \#2 \\
\hline MM_11_5_07 & 0.00026 & 52.3 & 73.2 & 1.625 & 0.0231 & $>0.997$ & Debris \#3 \\
\hline MM_11_6_07 & 0.00026 & 55.4 & 76.8 & 1.596 & 0.0220 & $>0.998$ & Debris \#3 \\
\hline MM_12_2_07 & 0.00052 & 46.1 & 101.4 & 2.252 & 0.0155 & $>0.999$ & Debris \#3 \\
\hline MM_12_3_07 & 0.00052 & 37.6 & 98.2 & 2.579 & 0.0179 & $>0.999$ & Debris \#3 \\
\hline MM_13_1_07 & 0.00104 & 21.7 & 99.9 & 3.123 & 0.0236 & $>0.998$ & Debris \#3 \\
\hline MM_13_2_07 & 0.00104 & 19.5 & 90.0 & 3.224 & 0.0270 & $>0.999$ & Debris \#3 \\
\hline MM_15_5_07 & 0.00052 & 24.8 & 112.3 & 2.433 & 0.0162 & $>0.998$ & Debris \#4 \\
\hline MM_15_6_07 & 0.00026 & 45.1 & 82.9 & 2.284 & 0.0208 & $>0.998$ & Debris \#4 \\
\hline
\end{tabular}


Table 8 Swebrec function parameters for magnetic mortar specimens from curve fitting (continued)

\begin{tabular}{lccccccc}
\hline Mortar & $\Pi_{1}$ & $x_{50}$ & $x_{\max }$ & $b$ & $s_{50}$ & $R^{2}$ & Confinement \\
\hline MM_15_13_07 & 0.00104 & 14.9 & 52.7 & 2.579 & 0.0342 & $>0.997$ & Debris \#4 \\
MM_15_14_07 & 0.00052 & 26.9 & 75.7 & 2.751 & 0.0247 & $>0.999$ & Debris \#4 \\
MM_1_1_05 & 0.00052 & 15.2 & 45.5 & 2.269 & 0.0340 & $>0.998$ & Free \\
MM_1_2_05 & 0.00052 & 14.1 & 49.8 & 2.364 & 0.0332 & $>0.996$ & Free \\
MM_1_6_05 & 0.00052 & 15.3 & 49.0 & 2.445 & 0.0343 & $>0.999$ & Free \\
MM_2_A_05 & 0.00052 & 14.9 & 70.2 & 2.570 & 0.0278 & $>0.997$ & Free \\
MM_2_B_05 & 0.00052 & 14.5 & 64.4 & 2.443 & 0.0282 & $>0.998$ & Free \\
MM_3_1_05 & 0.00052 & 17.0 & 54.6 & 2.397 & 0.0302 & $>0.998$ & Free \\
MM_5_2_05 & 0.00104 & 8.3 & 40.4 & 1.956 & 0.0373 & $>0.999$ & Free \\
MM_5_9_05 & 0.00026 & 25.5 & 78.1 & 2.726 & 0.0239 & $>0.999$ & Free \\
MM_5_4_05 & 0.00052 & 16.5 & 60.0 & 2.450 & 0.0288 & $>0.999$ & Free \\
MM_5_10_05 & 0.00052 & 13.1 & 60.5 & 2.679 & 0.0334 & $>0.998$ & Free \\
MM_11_1_07 & 0.00052 & 15.2 & 45.0 & 2.453 & 0.0372 & $>0.997$ & Free \\
MM_12_5_07 & 0.00052 & 14.0 & 45.0 & 2.545 & 0.0389 & $>0.998$ & Free \\
MM_13_4_07 & 0.00052 & 16.1 & 46.7 & 2.341 & 0.0341 & $>0.997$ & Free \\
MM_14_2_07 & 0.00052 & 17.1 & 51.4 & 2.452 & 0.0325 & $>0.998$ & Free \\
MM_15_8_07 & 0.00052 & 13.9 & 46.1 & 2.663 & 0.0400 & $>0.999$ & Free \\
MM_15_9_07 & 0.00052 & 15.1 & 46.9 & 2.546 & 0.0372 & $>0.999$ & Free \\
\hline & & & & & & &
\end{tabular}

All test data have not been presented because when $\Pi_{1}<0.00026$ the natural upper limit of fragment size is reached, i.e., the radius of $70 \mathrm{~mm}$ of the cylinder. For full-scale conditions, this region is not of great importance, but indicates the limit of the effect of confinement. In the range $0.00026<\Pi_{1}<0.00104$ in the log-log diagram, there seems to exist well defined and straight slopes for each confining condition. For a sufficiently large specific charge, the influence of the confinement on $x_{50}$ is an increase in the average sizes of over $100 \%$, depending on confining material.

For confined shots with debris \#1, the scatter of fragmentation has been identified as a porosity effect (Johansson et al., 2008). Some of these tests were made under induced confining stresses, i.e., reducing the volume of void in the granular material by decreasing diameter with a slotted and flanged steel cylinder that was tightened like a corset.

In full scale, the region of interest is when $\Pi_{1}>0.00026\left(q>0.65 \mathrm{~kg} / \mathrm{m}^{3}\right)$ and the individual fits can be achieved with the following equations:

$$
\begin{array}{ll}
x_{50}(\mathrm{~mm})=0.03 / \Pi_{1}^{0.81} & \text { for free face } \\
x_{50}(\mathrm{~mm})=0.07 / \Pi_{1}^{0.80} & \text { for debris \#1 } \\
x_{50}(\mathrm{~mm})=0.13 / \Pi_{1}^{0.76} & \text { for debris \#2 } \\
x_{50}(\mathrm{~mm})=0.19 / \Pi_{1}^{0.70} & \text { for debris \#3 } \\
x_{50}(\mathrm{~mm})=0.12 / \Pi_{1}^{0.71} & \text { for debris \#4. }
\end{array}
$$


The power of the $q$-factor lies between 0.70 and 0.81 for all confining conditions tested. This is quite close the power 0.8 in the Kuz-Ram (Cunningham, 1987) equation. As expected, the porosity clearly influences the fragmentation, which can be seen by the porosity differences between debris \#1 and \#3, which were made of the same initial material. The average $\mathrm{P}$-wave velocities in the two material compositions do not differ to any great extent; they both appear to lie in the same range of $1100-1200 \mathrm{~m} / \mathrm{s}$. Their densities in Table 5 are, however, porosity dependent and they differ.

For a given specific charge, as in Figure 10 the amount of fines is higher for both debris \#1 and debris \#2, which could be explained by that under these conditions the blasted material is allowed to move more, so fines from cracks are produced to a greater extent.

Figure $9 x_{50}$ vs. $\Pi_{1}$ for all tested confining materials

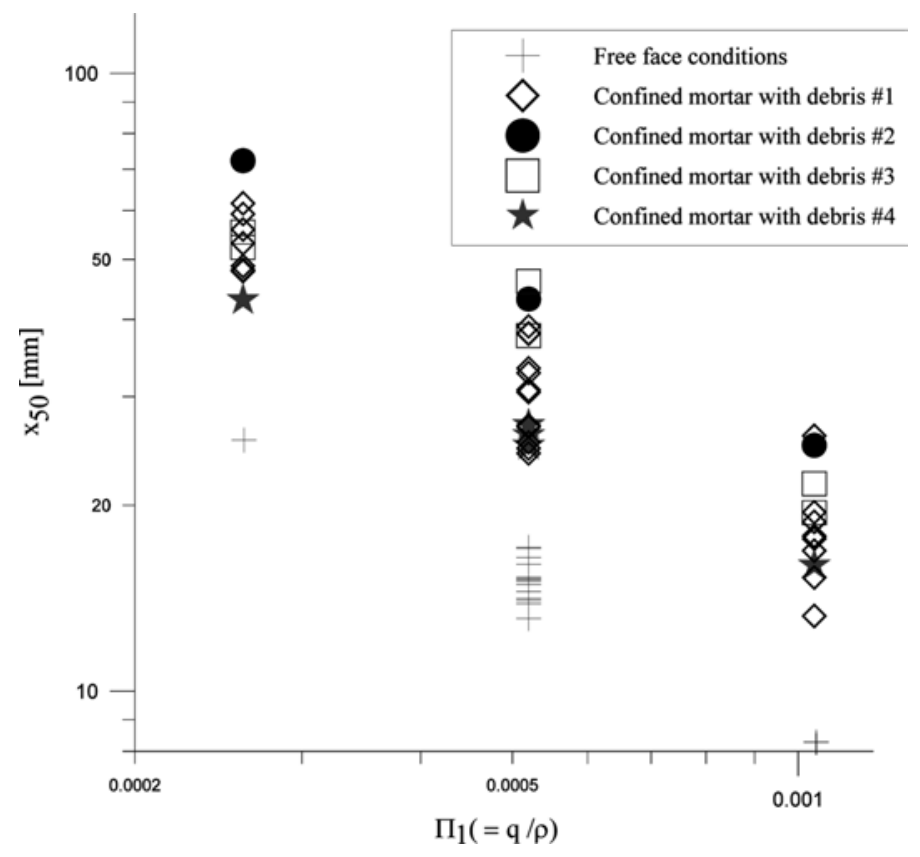

\subsection{Varied specimen length}

As seen in Figure 2, the hole length/burden ratio in an SLC-ring varies from 8 to 18 . For practical reasons, the L/R ratio was set to 4 in most of our tests, owing to the weight of the masses that had to be handled and sieved. As a control, 4 shots with $L / R=8$ were made to investigate the effect of the length ratio. As seen in Figure 11, the fragmentation is practically independent of the $\mathrm{L} / \mathrm{R}$ ratio except for sizes less than $1 \mathrm{~mm}$. One of the assumptions in the dimensional analysis was that the fragmentation could be seen in a $2 \mathrm{D}$ situation (i.e., independent of specimen length). This assumption could be seen as correct, looking at the fragmentation results in Figure 11. 
Figure 10 Fragmentation curves for magnetic mortar specimens with different confinements at $\Pi_{1}=5.2 \times 10^{-4}$

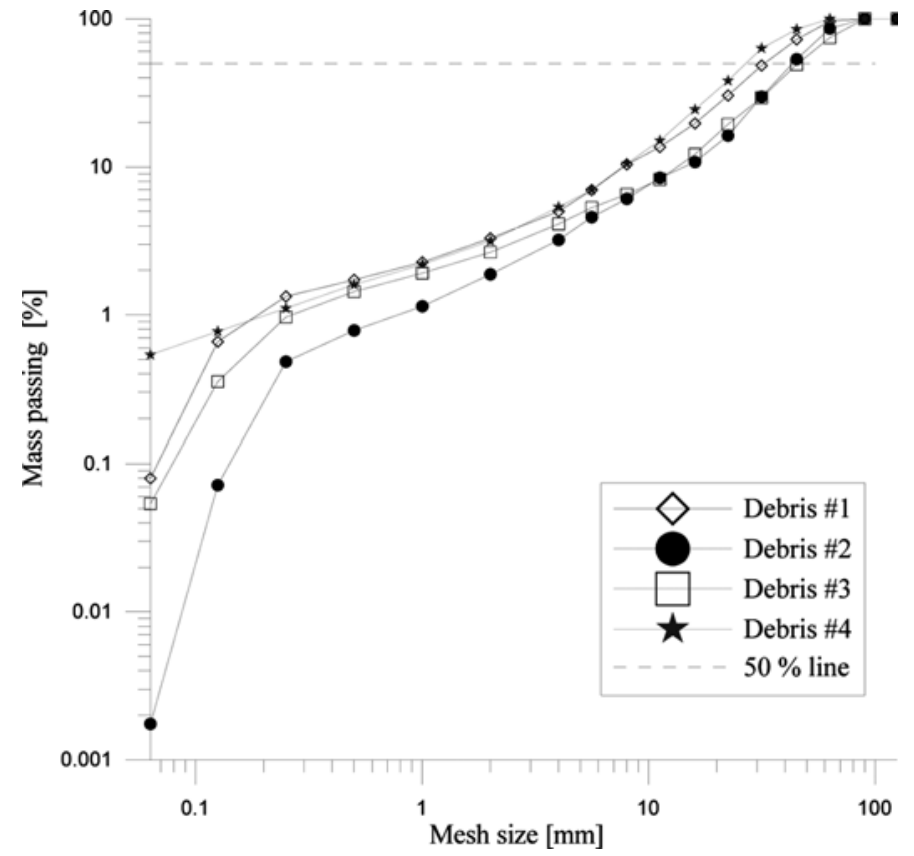

Figure 11 Fragmentation for specimens with different length/burden ratios at $\Pi_{1}=5.2 \times 10^{-4}$ $\left(q=1.3 \mathrm{~kg} / \mathrm{m}^{3}\right)$

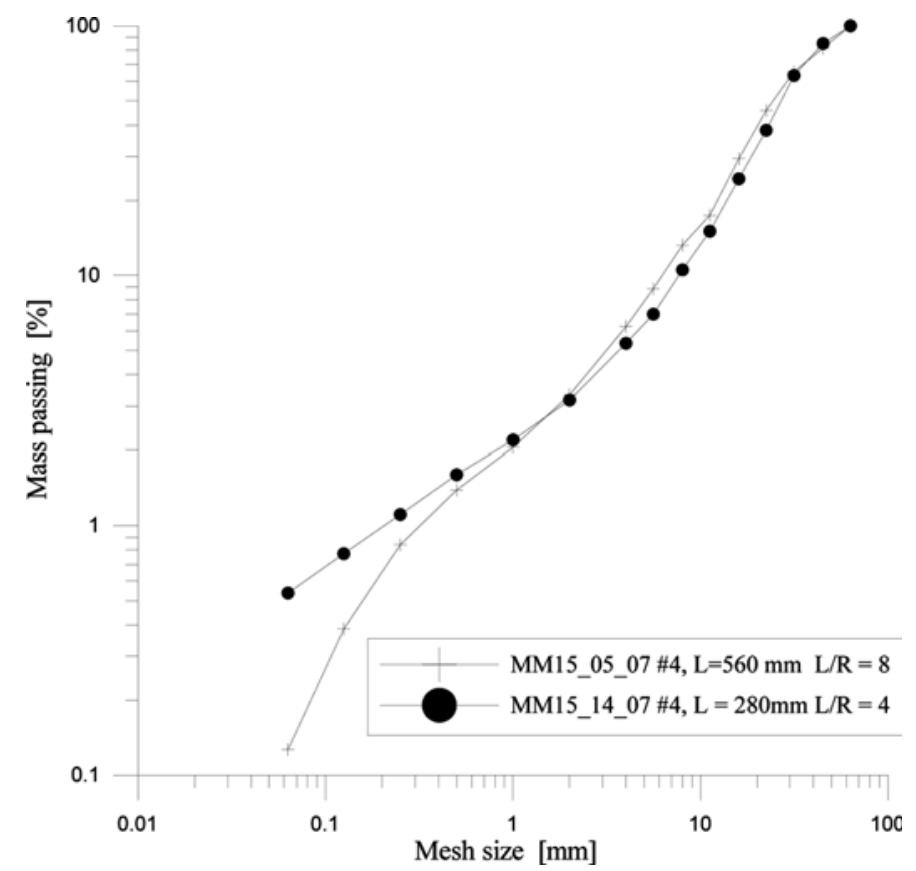




\section{Analysis}

The dominating failure mechanism in blasting is tensile failure (Field and Ladegaard-Pedersen, 1971); therefore, it could be assumed that the reflected stress wave will mainly influence the fragmentation. In the dimensional analysis, an impedance ratio (product of $\Pi_{2}$ and $\Pi_{10}$ ) had been identified as a possible influence on the fragmentation. By introducing the acoustic impedance values for the two materials, the cylinder $(Z)$ and the debris $\left(Z_{a}\right)$ assuming $1 \mathrm{D}$ state, the stress wave reflection and velocity transmission coefficients at the specimen debris interface could be calculated (Mavko, 1998). This factor had been identified as vital for the blastability of a material in earlier research (Vutukuri and Rustan, 1983). These relationships can be seen later, stated in terms of the stress wave reflection coefficient for 1D wave propagation:

Stress wave coefficient, $\operatorname{Re}=\left(Z-Z_{a}\right) /\left(Z+Z_{a}\right)=f\left(\Pi_{2}, \Pi_{10}\right)=\Pi_{2}^{\prime}$

where

$Z=\rho \cdot c_{p}$, i.e., acoustic impedance of the specimen material

$Z_{a}=\rho_{a} \cdot c_{p a}$, i.e., acoustic impedance of the confining material.

Under fully free face conditions, the entire wave is reflected, giving a maximum tensile wave amplitude (reflection coefficient $=1$ ) in the specimen. With the different debris materials, a varying degree of the wave is reflected. Thus, all tests will be analysed in the same process, i.e., from free face shots to heavily confined shots for which the coefficient $\operatorname{Re}$ is $<1$.

Since the dominating failure mechanism is tensile, the dimensional analysis shows that the product $\Pi_{8}$ could be one alternative to link magnetite and magnetic mortar properties and results.

These three products are used as the main physical descriptions of the materials involved in the blasting process. As seen in Figure 9, the fragmentation shows a non-linear behaviour, which is linear in log-log scale. Therefore, a suitable approach is a multiple non-linear regression model. After some preliminary runs, the model equation in the multiple linear regression analysis was based on the dimensional analysis (i.e., the logarithmic versions of these equations were used):

$$
x_{50} / R=\Pi_{1}^{\alpha 1} \cdot \Pi_{2}{ }^{\alpha 2} \cdot \Pi_{8}^{\alpha 3} \cdot \mathrm{F}\left(\Pi_{3}, \Pi_{4}, \Pi_{5}, \Pi_{6}, \Pi_{7}, \Pi_{9}\right) .
$$

$R$ is constant for all samples; therefore, it can be merged into $F$. If the influence of $F$ is thought to be stable, it could be replaced by a constant $B$. The suggested formula is then:

$$
x_{50}=\mathrm{B} \cdot \Pi_{1}^{\alpha 1} \cdot \Pi_{2}{ }^{\alpha 2} \cdot \Pi_{8}^{\alpha 3} \text {. }
$$

The majority of the tests were made on mortar models so a suitable initial step is to keep $\Pi_{8}$ constant, i.e., to only evaluate the model for magnetic mortar (62 observations) and the primary effect of $\Pi_{1}$ and $\Pi_{2}$. The regression analysis gives the following relationship:

$$
x_{50}[\mathrm{~mm}]=0.053 \cdot \Pi_{1}{ }^{-0.75} \cdot \Pi_{2}{ }^{2}-1.72 \cdot \Pi_{8}{ }^{0} .
$$

As seen in Table 9 for this model, the coefficient of determination $\left(R^{2}\right)$ is higher than $90 \%$ and a fair indicator that this model does predict the fragmentation sufficiently well. Studying the model's $\alpha$-values, the quotient $\alpha_{1} / \alpha_{2}$ is around 2 and this could be further 
elaborated. By squaring the reflection coefficients $\left(\Pi_{2}{ }^{2}\right)$, the energy of the waves will be represented (Mavko, 1998). This wave coefficient in combination with the energy input, $\Pi_{1}$ would be a good representation of the energy content in the reflected wave. The reflection coefficients for all tests were, therefore, squared and multiplied with $\Pi_{1}$, i.e., $\Pi_{1 \mathrm{e}}=\Pi_{1} \cdot\left(\Pi_{2}^{\prime}\right)^{2}$ is an effective specific charge (dimensionless though). This approach will not influence the capability of the model to any extent. $R^{2}$ still lies above $90 \%$, but with fewer parameters and perhaps a clearer physical meaning. This reminds strongly of the reasoning about wave reflection losses in underwater blasting by Langefors and Kihlström (1963).

The introduction of $\Pi_{8}$ provides a correlation between the well-defined mortar and a geological material (magnetite) on the basis of tensile fracturing. Following the suggested formula, the prediction capability is fair. The $R^{2}$ value decreases from $\sim 90 \%$ down to $85 \%$ independently of what model approach is used. Since the magnetite specimens were all blasted with the same $q$-value, one would not expect them to change the value of $\alpha_{1}$.

The result of the analysis is visualised by plotting the predicted $x_{50}$-values vs. the actual $x_{50}$-values in Figure 12. Here, only magnetic mortar is analysed, i.e., $\Pi_{8}$ is 0.144 (Table 6).

Table 9 Multiple regression analysis output for $x_{50}$

\begin{tabular}{lllllllll}
\hline $\begin{array}{l}\text { Model } \\
\text { No. }\end{array}$ & Model equation & $\begin{array}{l}\text { Specimen } \\
\text { materials }\end{array}$ & $\begin{array}{c}\text { No. of } \\
\text { samples }\end{array}$ & $B$ & $\alpha_{1}$ & $\alpha_{2}$ & $\alpha_{3}$ & $R^{2} / R^{2}{ }_{a d j}$ \\
\hline 1 & $\mathrm{~B} \cdot \Pi_{1}^{\alpha 1} \cdot \Pi_{2}{ }^{\alpha 2} \Pi_{8}{ }^{\alpha 3}$ & Magnetic mortar & 62 & 0.053 & -0.75 & -1.72 & 0 & $90.7 \% / 88.5 \%$ \\
2 & $\mathrm{~B} \cdot\left(\Pi_{1} \cdot\left(\Pi_{2}{ }^{2}\right)^{\alpha 1} \cdot \Pi_{8}^{\alpha 3}\right.$ Magnetic mortar & 62 & 0.037 & -0.80 & - & 0 & $90.4 \% / 88.4 \%$ \\
3 & $\mathrm{~B} \cdot \Pi_{1}^{\alpha 1} \Pi_{2}{ }^{\alpha 2} \cdot \Pi_{8}^{\alpha 3}$ & $\begin{array}{l}\text { Magnetic mortar, } \\
\text { magnetite, excl } \\
\text { debris \#2 }\end{array}$ & 77 & 2.28 & -0.71 & -1.70 & 0.40 & $86.8 \% / 86.2 \%$ \\
4 & $\mathrm{~B} \cdot\left(\Pi_{1} \cdot\left(\Pi_{2}^{\prime}\right)^{2}\right)^{\alpha 1} \cdot \Pi_{8}^{\alpha 3} \begin{array}{l}\text { Magnetic mortar, } \\
\text { magnetite, excl } \\
\text { debris \#2 }\end{array}$ & 77 & 3.49 & -0.79 & - & 0.53 & $86.1 \% / 85.7 \%$ \\
\hline
\end{tabular}

It is clear that the mixture in debris \#2 produces outliers and involves properties that are hard to account for due to its two-component content. One aspect could also be that it is the accelerometer measurements in these tests that fail. They were made with a subsonic emulsion, whose VOD had lower P-wave speed that the blasting material and not with the PETN cord that was used in all shots in Figure 12. The median error in the prediction model is roughly $10 \%$.

When including the 18 magnetite cylinders, $\Pi_{8}$ is introduced, which has got a range between 0.06 and 0.144 depending on model material (model no. 4 in Table 9). As seen in Figure 13 the scatter is larger than for the magnetic mortar alone. Probably the magnetite is a less homogeneous material and using it as a model material would risk obscuring some of the other observed effects. The magnetite data is, however, included in the analysis and important for the regression input $\left(\Pi_{8}\right)$. There are some properties of the magnetite that the model does not fully take into account, which can be seen in Figure 13, where the model over-predicts or under-predicts the fragmentation depending on ore type. 
Figure 12 Measured $x_{50}$ vs. predicted $x_{50}$ based on model 2

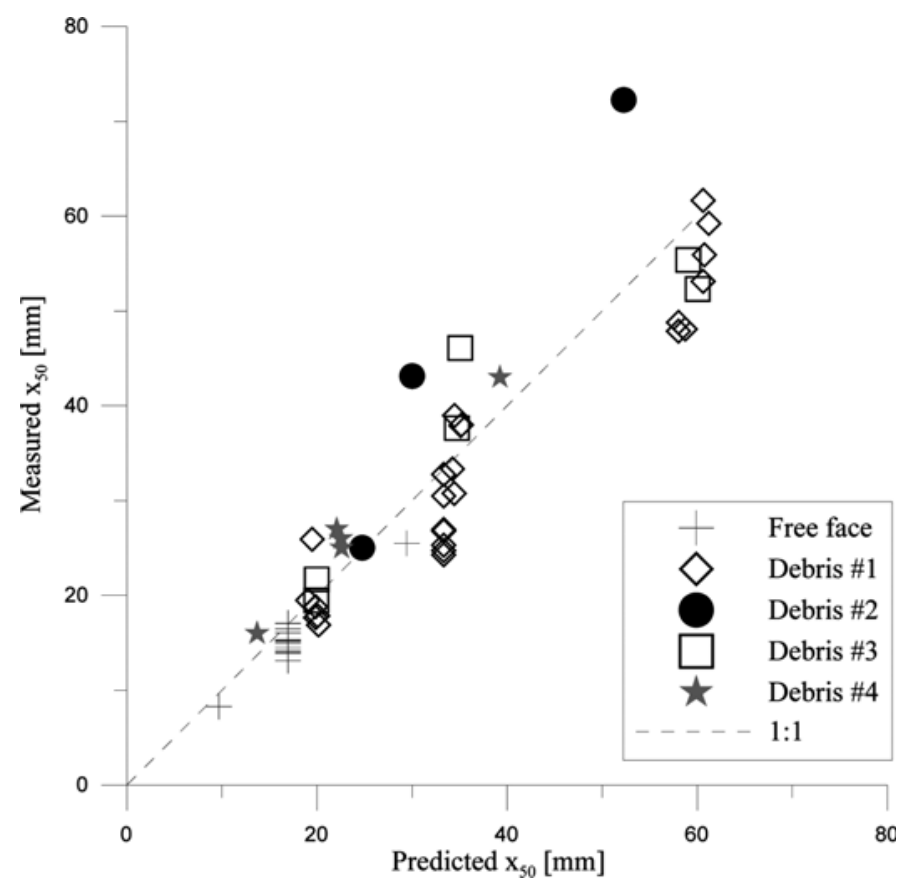

Figure 13 Measured $x_{50}$ vs. predicted $x_{50}$ based on model 4, including the different magnetite ores

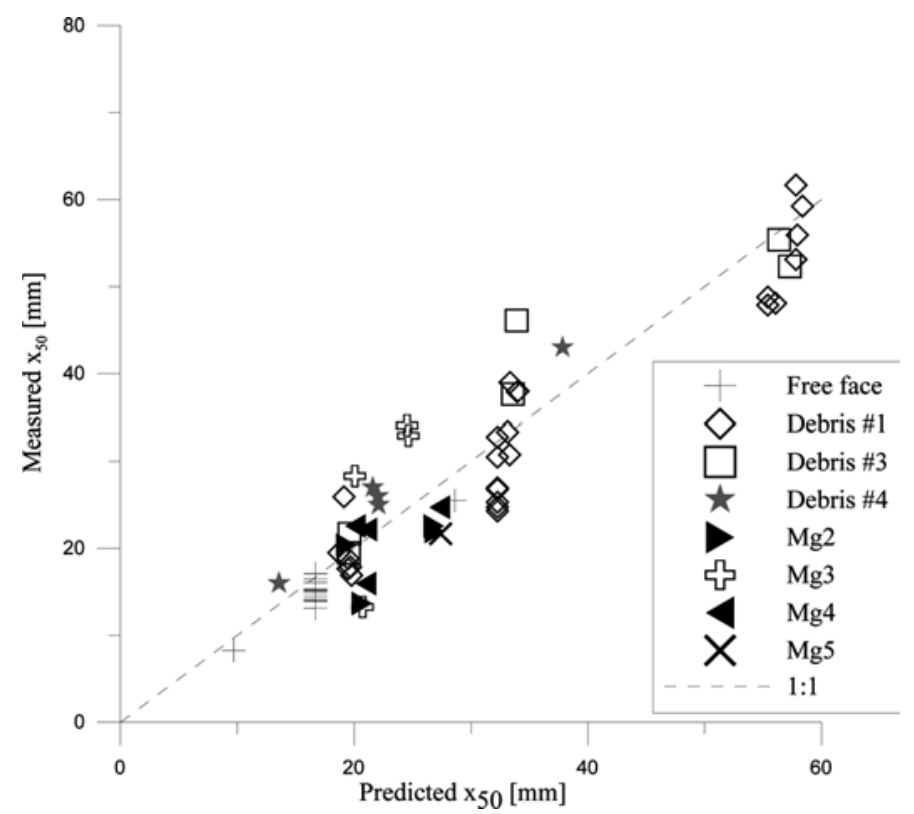

$\mathrm{Mg}_{2}$ and $\mathrm{Mg}_{4}$ are under-predicted for nearly all tests, but $\mathrm{Mg}_{3}$ and $\mathrm{Mg}_{5}$ are showing more reasonable predictions. The median error in the model is around $17 \%$ for the different magnetite types. The data of the magnetite's dynamical properties originates from nearby 
locations, so the capability of the model is restricted to some degree. $\Pi_{8}$ may not be sufficient enough as a material parameter to completely describe the fragmentation behaviour. Table 1 contains individual data for $\sigma_{B T}$, but not for $c_{p}$. Choosing a different $c_{P}$-value will shift the data in Figure 13 as a group, but not really improve the fit. If individual $c_{p}$ data had been available, this might have improved the fit though.

\section{Discussion and conclusions}

The understanding of the behaviour in confined blasting environments as in sub-level caving is an important aspect in the long-term optimisation of the mining operation.

The full-scale situation has its obstacles to overcome in terms of fundamental understanding, as well-defined input parameters for example geometry, scale, number of tests, etc. The scale will strongly influence the number of tests for instance.

Full-scale sieving of a blast ring at LKAB in magnetite quality $\mathrm{Mg}_{4}$ has recently been made (Wimmer et al., 2008), where the first $7.5 \%$ of the total ring mass was taken out directly after the blast. The average fragment size from sieving six buckets was $x_{50 f s}=86 \mathrm{~mm}$. This is much smaller than the common estimate in the mine that $x_{50 f s} \approx 250 \mathrm{~mm}$. The explanation could be that the fragmented ore in Wimmer's tests originated from the bottom of the ring or from the vicinity of the blast holes (Power, 2004a). Each hole was on average charged with about $260 \mathrm{~kg}$ emulsion, which has fairly the same volume strength as ANFO. The specific charge in this region of an SLC-ring with $B_{f s}$ (burden in full scale) $=3 \mathrm{~m}$ and where $L_{f s}$ (blasthole length in full scale) $\approx 10 \mathrm{~m}$ and $\mathrm{Q}_{\mathrm{fs}}$ (explosive weight per hole in full-scale) $\approx 100 \mathrm{~kg}$ amounts to $(q / \rho)_{f s}=0.40-$ $0.45 \mathrm{~kg} /$ ton (Selldén, 2001), which is an increase by a factor of 1.7 from the average $0.26 \mathrm{~kg} /$ ton $\left(1.3 \mathrm{~kg} / \mathrm{m}^{3}\right)$.

Our present model tests in magnetite type $\mathrm{Mg}_{4}$ gave the result that under confined conditions $x_{50}$ was $33.5 \pm 0.6 \mathrm{~mm}$. The charge size has been $Q_{m s}=0.020 \mathrm{~kg} / \mathrm{m} \cdot 0.28 \mathrm{~m}=0.0056 \mathrm{~kg}$ and $(q / \rho)_{\mathrm{ms}}=1.3 / 5=0.26 \mathrm{~kg} /$ ton. So how can we scale up these results when our model tests looked only at the effect of materials and charge concentration, neither at explosive, nor at geometry and with a few exceptions nor on geometrical scale? The Kuz-Ram prediction equation for $\mathrm{x}_{50}$ (Cunningham, 1987) includes the effects of explosive through weight strength $\mathrm{s}_{\mathrm{ANFO}}$ relative to ANFO and of geometrical scale through the absolute size $Q$ of the charge.

$$
x_{50}=A \cdot Q^{1 / 6} \cdot\left(115 / s_{\mathrm{ANFO}}\right)^{19 / 30} / q^{0.8} .
$$

There is also an indirect size effect in that the rock mass factor A would have a higher value for the competent model scale cylinders than for a larger scale, fractured rock mass. In a sense, the latter effect could be included in our equation by the factor $\Pi_{8}$ since the strength $\sigma_{B t}$ is expected to decrease with sample size.

In an extension of Kuznetsov's equation (12), Ouchterlony (2009b) chose to express the geometrical scale not through $Q$ but through burden $(B)$, spacing $(S)$ and length $(L)$. The explosive energy is defined as $e$ in the expression. For a cylindrical specimen where $B=R$, equation (27) gave

$$
x_{50}=A^{\prime} \cdot(L / B)^{1 / 3} \cdot B /\left(q \cdot \mathrm{e} \cdot B^{0.4}\right)^{\alpha},
$$

where $\alpha=0.84$ was found. Surprisingly, the factor $q \cdot e \cdot B^{0.4}$ is the core part of a dimensionless parameter. Equation (13) helped to explain why experimentalists have 
found different powers of $q$-dependence when they change the charge size in a specimen of given size or when they change the specimen size but keep the charge size the same.

One of the underlying assumptions behind equation (13) is a strength model that is not dependent on specimen size, but on strain rate. Introducing a size-dependent strength would increase the exponent value 0.4 of $\mathrm{B}$, mitigating the size dependency implied in the equation. The factor $\Pi_{8}$ in our model equation has the same effect, see before.

Combining equation (13) and our model equation with a slightly modified exponent values, we could write

$$
x_{50}=A^{\prime} \cdot(L / B)^{1 / 3} \cdot B /\left(q \cdot e \cdot \Pi_{2}^{\prime} \cdot B^{0.4}\right)^{0.8} \cdot\left(\sigma_{B T} / \rho c_{P}^{2}\right)^{0.5} .
$$

The volume dependence would be expected to be in the range $\sigma_{B T} \propto 1 / \mathrm{V}^{(1 / 12}$ to $\left.1 / 6\right)$, with $1 / 6$ referring to tensile strength and $1 / 12$ to compressive, see Persson et al. (1994). Normalising at lab-scale one obtains

$$
x_{50}=A^{\prime \prime} L^{1 / 4} \cdot B^{1 / 6} /\left(q \cdot e \cdot \Pi_{2}{ }^{\prime}\right)^{0.8} \cdot\left(\sigma_{B T \mathrm{lab}} / \rho c_{P}{ }^{2}\right)^{0.5} .
$$

Taking the ratio of the prediction equation for full-scale (fs) and model scale (ms), then $A^{\prime \prime}, \Pi_{2}^{\prime}$ and the strength factor cancel and we obtain with $e_{m s} \approx 6.0 \mathrm{MJ} / \mathrm{kg}$ and $e_{f s} \approx 3.4 \mathrm{MJ} / \mathrm{kg}$ that

$$
\begin{aligned}
\left(x_{50 \mathrm{fs}} / x_{50 \mathrm{~ms}}\right)= & \left(\mathrm{L}_{\mathrm{fs}} / \mathrm{L}_{\mathrm{ms}}\right)^{1 / 4} \cdot\left(B_{f s} / B_{m s}\right)^{1 / 6}\left[\left(e_{m s} \cdot q_{m s}\right) /\left(e_{f s} \cdot q_{f s}\right)\right]^{0,8} \approx(10 / 0.28)^{1 / 4} \cdot(3 / 0.07)^{1 / 6} \\
& {[(6.0 \cdot 0.26) /(3.4 \cdot 0.425)]^{0,8}=4.9 . }
\end{aligned}
$$

The real fragment size ratio is, however, $86 / 33.5=2.6$. Thus, we miss out by a factor of about 2 . There could be several reasons for this:

- Wimmer's study (2008) showed that the magnetite pieces that were sieved were quite friable, they broke easily during the sieving. This would give a progressively finer fragmentation after sieving than after blasting.

- Wimmer also mentions the so-called autogenous grinding of the blasted ore as it is caving into the draw-point as possibly causing a secondary fragmentation.

- In the first $7.5 \%$ of the ring, we are de facto sampling a much higher loading regime than the relatively low specific charge of $0.40-0.45 \mathrm{~kg} / \mathrm{m}^{3}$ would suggest. Doubling this ratio would give a predicted fragment size ratio of 2.8 , which is quite close to the real value 2.6.

- The decoupling of the cord may lower the effective shock energy content $e_{f s}$ in that the borehole pressure is now much lower. To use $e_{f s}=6.0 \mathrm{MJ} / \mathrm{kg}$ for decoupled PETN cord may in other words be too high.

- Referring back to Figure 10, there seemed to be no effect of specimen length L when $\mathrm{L}$ was doubled. Equation (14b) would have predicted a factor of $2^{1 / 4} \approx 1.19$ increase in $x_{50}$. If we consider two facts, first that sieving always picks up the two smallest dimensions of a fragment and second that an elongated fragment breaks more easily one might tentatively lower the exponent of the L-ratio. Since its present value is $(10 / 0.28)^{1 / 4}=2.45$, this would have some effect.

The above-mentioned list contains a number of reasonable physical factors that all push the predicted fragment size ratio of the blasted magnetite towards the real value, not away from it. 
If we instead focus on a whole SLC round with the estimated $x_{50 \mathrm{fs}} \approx 250 \mathrm{~mm}$ and $L_{f s} \approx 30 \mathrm{~m}$ and $q_{f s}=0.26 \mathrm{~kg} / \mathrm{m}^{3}$, then the predicted fragment size ratio from equation (15) would become

$$
\left(x_{50 f s} / x_{50 m s}\right) \approx(30 / 0.28)^{1 / 4} \cdot(3 / 0.07)^{1 / 6} \cdot[(6.0 \cdot 0.26) /(3.4 \cdot 0.26)]^{0,8}=9.5 .
$$

The estimated real fragment size ratio would be $250 / 33.5=7.5$, which is relatively seen closer than before. Too much should not be made of this fact however. The important fact is that despite the enormous difference in scale between our model tests and a full-SLCring, the compound model equation in equation (14b) gives relatively reasonable results when tried on the SLC-ring.

The main conclusions of this work are therefore:

- The test set-up developed has reproducible conditions and produces reliable fragmentation results.

- The confinement reduces the fragmentation considerably, i.e., makes it coarser, both for the magnetite and for the magnetic mortar. The effect has been quantified in terms of impedance ratio and specimen strength.

- In all cases where the magnetite and magnetic mortar specimens broke up into fragments, the basic Swebrec function describes the fragmentation obtained quite well in the size range $0.25 \mathrm{~mm}$ and up.

- The small-scale test set-up allowed a large number of tests to be performed in this project. Thus, sufficient data for a statistical analysis was obtained.

- Regression analysis of the average fragmentation data resulted in prediction equations that involve the specific charge, the impedance ratio at the specimen debris interface and tensile strength of the model material as the main influencing factors.

- The prediction equations may be expected to hold when the scale of the tests is increased somewhat. If this carries all the way to full-scale ring, blasts remain to be seen though.

\section{Acknowledgements}

The writers thank the LKAB mining company and the Mass Mining Technology project sponsored by LKAB, De Beers, Rio Tinto, Codelco, BHP Billiton (Stainless Steel and Base Metals), Newcrest Mining, Anglo Base Metals, Xstrata, Orica, Inco, CVRD, Sandvik, Sustainable Minerals Institute of the University of Queensland (especially the project coordinator Gideon Chitombo) and Itasca. Special thanks go to Torbjörn Naarttijärvi and Stig Fjellborg of LKAB for invaluable ideas about the set-up.

\section{References}

Atlas Copco (2004) Underground Mining Methods - First Edition, Reference Editions Ltd for Atlas Copco Rock Drills AB.

Cullum, A.J. (1974) The Effects of Confined Blasting on Rock Fragmentation and How Flow Characteristics in Sublevel Caving, MSc Thesis, Brisbane, Univ. of Queensland, p.161. 
Cunningham, C.V.B. (1987) 'Fragmentation estimations and the Kuz-Ram model - four years on', in Fourney, W.L. and Dick, R.D. (Eds): Proc 2nd Int. Symp on Rock Fragmentation by Blasting, Bethel CT, USA, SEM, pp.475-487.

Field, J.E. and Ladegaard-Pedersen, A. (1971) 'The importance of the reflected stress wave in rock blasting', Intl. J. Rock Mechs. and Mining Sci., Vol. 8, Pergamon Press, UK, pp.213-226.

Gustafsson, P. (1998) Waste Rock Content Variations during Gravity Flow in Sublevel Caving: Analysis of Full-scale Experiments and Numerical Simulations, PhD Thesis 1998:10, Div of Rock Engineering, Luleå Univ. Techn, Luleå, Sweden.

Johansson, D. (2008) Fragmentation and Waste Rock Compaction in Small-scale Confined Blasting, Licentiate thesis 2008, Luleå Univ. Techn, Luleå, p.30.

Johansson, D., Ouchterlony, F., Edin, J., Martinsson, L. and Nyberg, U. (2008) 'Blasting against confinement, fragmentation and compaction in model scale', in Schunnesson, H. and Nordlund, E. (Eds.): MassMin 2008, Proc. 5th Int. Conf. \& Exhib. on Mass Mining, Rotterdam, Balkema, pp.681-690.

Johansson, D. (2010) 'Dynamic blast compaction of some granular materials: small-scale tests and numerical modelling of a mining-related problem', Int. J. Mining and Mineral Engineering, Vol. 2, No. 2, pp.79-100.

Langefors, U. and Kihlström, B. (1963) The Modern Technique of Rock Blasting, 1st ed., Almqvist \& Wiksell, Stockholm.

Liu, H., Kou, S. and Lindqvist, P-A. (2005) Characterization of Ore Properties in LKAB Mines, Preliminary Project Report to LKAB 2005-04-13, LKAB, Kiruna, Sweden.

Maripuu, R. (1968) Undersökning av siktanalys och styckeform från skivrasbrytningen vid LKAB, Kiruna, Diploma thesis, Royal Inst. of Techn. (KTH) (in Swedish), Stockholm, p.30.

Mavko, G. (1998) Rock Physics Handbook: Tools for Seismic Analysis in Porous Media, ISBN 0521620686, Cambridge Univ. Press, UK.

Miklautsch, A. (2002) Experimental Investigation of the Blast Fragmentation Behaviour of Rocks and Concrete, Diploma thesis. Inst. für Bergbaukunde, Bergtechnik und Bergwirtschaft, Montanuniversität Leoben, Leoben, Austria, p.161.

Ouchterlony, F. (2005) 'The swebrec function: linking fragmentation by blasting and crushing', Mining Technology (Trans. Inst. Min. Metall. A), Vol. 114, pp.A29-A44.

Ouchterlony, F. (2009a) 'Fragmentation characterization; The Swebrec function and its use in blast engineering', in Sanchidrián, J.A. (Ed.): Rock Fragmentation by Blasting, Proc. 9th Intnl Symp. on Rock Fragmentation by Blasting, London, Balkema, pp.3-22.

Ouchterlony, F. (2009b) 'A common form for fragment size distributions from blasting and a derivation of a generalized Kuznetsov's $\mathrm{x}_{50}$-equation', in Sanchidrián, J.A. (Ed.): Rock Fragmentation by Blasting, Proc. 9th Intnl Symp. on Rock Fragmentation by Blasting, London, Balkema, pp.199-208.

Ouchterlony, F. and Moser, P. (2006) 'Likenesses and differences in the fragmentation of full-scale and model scale blasts', Fragblast 8, Proc. 8th Intnl Symp. on Rock Fragmentation by Blasting, Santiago, Chile, Editec SA, pp.207-220.

Persson, P.A., Holmberg, R. and Lee, J. (1994) Rock Blasting and Explosives Engineering, CRC Press, Boca Raton FL.

Power, G. (2004a) Modelling Granular Flow in Caving Mines: Large Scale Physical Modelling and Full Scale Experiments, $\mathrm{PhD}$ thesis, Univ. of Queensland, Brisbane, p.283.

Power, G. (2004b) 'Full scale SLC draw trials at ridgeway gold mine', in Karzulovic, A. and Alafaro, M.A. (Eds.): MassMin 2004, Proc. 4th Int. Conf. \& Exhib. on Mass Mining, Santiago, Chile, Editec SA, pp.225-230.

Selldén, H. (2001) 'Sublevel caving in LKAB- problems and possibilities', Proc. Discussion Meeting BK 2001, Swedish Rock Construction Committee (in Swedish), Stockholm, pp.63-78. 
Svahn, V. (2003) Generation of Fines in Bench Blasting, Licentiate Thesis, Dept. of Geology Publ A104, Chalmers Univ. of Techn., Gothenburg, Sweden.

Taylor, E.S. (1974) Dimensional Analysis for Engineers, Clarendon Press, Oxford.

Vutukuri, V.S. and Rustan, A. (1983) Influence of Physical Properties of Rock and Rock-like Material on Blastability in Crater and Slab Blasting, a Literature and Model Study, Report FG 8221, Swedish Mining Research Foundation: Luleå.

Wimmer, M., Ouchterlony, F. and Moser, P. (2008) 'The fragment size distribution of Kiruna magnetite, from model scale to run of the mine', in Schunnesson, H. and Nordlund, E. (Eds.): MassMin 2008, Proc. 5th Int. Conf. \& Exhib. on Mass Mining, Rotterdam, Balkema, pp.691-705. 